\title{
Hipovitaminose A em crianças de áreas rurais do semi-árido baiano
}

\author{
Vitamin A deficiency in children of rural zones, Northeast region of Brazil
}

\author{
Matildes da Silva Prado, Ana Marlúcia Oliveira Assis, Maisa Cruz Martins, \\ Maria da Purificação Araújo Nazaré, Ioná F. Bonfim Rezende, \\ Maria Ester Pereira Conceição
}
Escola de Nutriçāo da Universidade Federal da Bahia- Brasil (M. S. P., A. M. O. A.), Secretaria de Saúde do Estado - Salvador-Brasil (M. C. M., M. P. A. N.), Conselho Nacional de Desenvolvimento Tecnologico/CNPq-Brasilia, D. F. - Brasil (l. F. B. R., M. E. P. C. - bolsistas)

\begin{abstract}
Objetivou-se avaliar a distribuição e a magnitude da deficiência de vitamina A e o consumo dietético de 161 crianças de 6 a 72 meses de ldade, de áreas rurais do Município de Cansançăo-Bahia, Brasil. Os níveis de retinol sérico toram medidos pelo método espectrofotométrico (Bessey-Lowry modlficado pơ Araúlo e Flores, 1978). A média do retinol sérlco dlstribuluse homogeneamente entre as diferentes faixas etárias. Níveis inadequados de retinol sérico (deficiente $<10,0 \mu \mathrm{g} / \mathrm{dl} \theta$ baixos $<20,0 \mu \mathrm{g} / \mathrm{dl}$ ) foram detectados em $44,7 \%$ das crianças, caracterlzando a deficjéncia como problema de saúde pública. Os niveis de retinol sérico nāo mostraram associaçăo estatisticamente significante com sexo e idade das crianças, contudo as menores de 24 meses apresentaram prevalência mais alta de niveis inadequados. A principal fonte de vitamina $A$, disponivel para essas crianças, é representada pelos carotenóides, em especial beta-caroteno. Foi observada maior diversificaçāo no consumo dos allmentos de conteúdos moderado e baixo em vitamina A no grupo de 24 a 72 meses de idade, sem contudo assegurar niveis adequados de retinol sérico para este grupo etário.
\end{abstract}

Deficiência de Vitamina A, epidemiologia. Inquéritos sobre dieta. Populaçāo rural.

\section{Introdução}

A vitamina Aé tradicionalmente conhecida como um micronutriente essencial na manutenção da integridade do sistema ocular (Sommer e col. ${ }^{30}, 1986$; Olson $^{22}$, 1986; WHO ${ }^{16}, 1982$ ), sistema imune (Nauss $^{21}, 1986$ ), divisão e diferenciação celular (De Luca e col. ${ }^{9}, 1989$ ).

$O$ avanço no conhecimento sobre esse micronutriente permitiu estabelecer, também, a sua associaçăo com a morbi-mortabilidade infantil; esta associaçāo tem sido demonstrada em estudos observacionais (Sommer e col. ${ }^{29}, 1983$; Milton e col ${ }^{18}, 1987$; El Bushra e col. ${ }^{10}, 1992$ ). Estudos de intervenção, controlados, envolvendo crianças menores de seis anos de idade de áreas onde existe a deficiência nas formas clínicas ou subclínicas, têm confirmado a reduçāo na morbi-mortalidade para o grupo suplementado quando comparado com o controle (Muhilal e col. ${ }^{19}$, 1988; Daulaire e col. ${ }^{8}, 1992$;
Sommer e col. ${ }^{30}$, 1986; West e col. ${ }^{33}$, 1991; Rahmathullah e col. ${ }^{25}$, 1990; Milton e col. ${ }^{18}, 1987$; Barreto e col. ${ }^{4}, 1994$ ).

Essa deficiência geralmente apresenta-se acompanhada de outras carências nutricionais, e a desnutrição energético protéica é um exemplo (Venkataswamy e $\mathrm{col}^{31}, 1977$ ). É conhecido também que o processo metabólico, que envolve a vitamina A e seus precursores, depende da biodisponibilidade de outros nutrientes; a diminuiçăo das vitaminas $\mathrm{Ce} E$ na dieta contribui com a oxidação da vitamina A na luz intestinal e a carência de lipídeos compromete a absorção desse micronutriente em especial dos carotenóides.

Estudos desenvolvidos em vários países têm demonstrado que a deficiência está ainda associada com o desmame precoce e o consumo inadequado de alimentos fontes de vitamina $\mathbf{A}$ preformada ou carotenoídes (Mele e col. ${ }^{17}, 1991$; Newman ${ }^{20}, 1993$ ).

Esses fatores podem explicar a ampla difusão da deficiência de vitamina $\mathrm{A}$ nos países periféricos, 
onde se estima que 43 milhões das crianças menores de cinco anos de idade apresentam deficiência desse micronutriente (Vital ${ }^{32}, 1991$ ).

Existem evidências de que se a renda e o nível educacional elevam-se, a dieta ingerida toma-se mais diversificada e as manisfestaçð̌es da deficiência A diminuem e/ou não aparecem, (Beaton e col. ${ }^{6}, 1992$ ).

Não existem dados que caracterizem a distribuição e severidade da deficiência de vitamina A para toda a população brasileira; contudo, estudos observacionais isolados registram para a regiāo Nordeste inadequação dos níveis séricos de retinol, variando de 14,7 a $54,7 \% *$ (Batista Filho e Torres ${ }^{5}, 1982$ ); sinais clínicos foram detectados na década de 80 para essa mesma região (Santos e col. ${ }^{28}, 1983$ ).

$O$ presente estudo teve como objetivo avaliar a distribuição e magnitude da deficiência de vitamina A e o consumo dietético de crianças de seis a setenta e dois meses de idade, residentes em áreas rurais do Município de Cansanção-Bahia.

\section{Procedimentos Metodológlcos}

\section{Caracterização da Área}

O Município de Cansançāo está situado no Nordeste do Estado da Bahia, numa das regiões mais secas e quentes do trópico semi-árido, a uma distância de $350 \mathrm{~km}$ da capital, com superfície de 1.317 $\mathrm{km}^{2}$. Conforme o Censo Demográfico de 1991, apresenta uma população de aproximadamente 30.800 habitantes, sendo 23.900 residentes na zona rural e $6.900 \mathrm{na}$ área urbana (IBGE ${ }^{12}, 1991$ ).

A economia do município tem como sustentáculo as atividades agrícolas baseadas no cultivo de mandioca, milho, feijão e sisal; a atividade secundária e complementaré representada pela ovinocultura. A pecuária é exercida de forma extensiva, por pequena parcela de médios e grandes proprietários existentes na área (IBGE $\left.{ }^{12}, 1991\right)$.

\section{População}

Integra o presente estudo a população infantil de 6 a 72 meses de idade, cadastradas pelas Associaçres de Pequenos Agricultores, vinculadas ao Projeto Cansançāo (Gaudenzi e col. ${ }^{13}, 1982$ ), oriundas de familias de pequenos produtores rurais das localidades do Município de Cansanção-Bahia: Caetano, Capoeira, Lagoa das Moças e Lage de Gameleira. Apos conhecer os objetivos da investigação e os procedimentos para o diagnóstico da deficiência de vitamina $\mathrm{A}$, o voluntário responsável pela criança assinou um termo de consentimento e compareceu

\footnotetext{
* Dra. Leonor Maria Pacheco Santos - Escola de Nutrição da Universidade Federal da Bahia (Comunicação pessoal)
}

às escolas das localidades, com as crianças em jejum. Compareceram 223 crianças para a coleta de sangue; entretanto, nảo foi possível dosar o retinol en 62 delas, porque a quantidade de sangue foi insuficiente ou a criança năo colaborou. Assim, o estudo foi realizado com 161 crianças.

Para o estudo da ingestão dietética, foi constituída uma subamostra aleatória, em relaçāo à população de estudo, representando $76,8 \%$ das crianças com informações da dosagem do retinol. Os dados foram coletados por professores e estudantes da Escola de Nutriçāo da UFBA, no período de dezembro de 1992 a janeiro de 1993, época de safra de alimentos fontes de vitamina $\mathrm{A}$.

\section{Avaliaçăo Bioquímica}

De cada criança, em jejum, foram coletados $5 \mathrm{ml}$ de sangue por venopunção, utilizando-se material descartável. As amostras de sangue foram colocadas em tubos de vacutener, devidamente protegidas da luz. Após a retração do coágulo (cerca de 20 min após a coleta), este material foi centrifugado a $7.000 \mathrm{rpm}$ durante $10 \mathrm{~min}$, para separaçăo do soro; e imediatamente congelado a $-15^{\circ} \mathrm{C}$. As amostras foram transportadas sob refrigeração em caixas de isopor, cuidadosamente lacradas, até o Laboratório de Bioquímica da Nutrição da UFBA, para análise. O método bioquímico espectrofotométrico de Bessey-Lowry, modificado por Araújo e Flores ${ }^{2}$ (1978), foi adotado para determinar os níveis de retinol sérico. As amostras foram dosadas em duplicata.

Para interpretação dos resultados utilizou-se os critérios propostos pelo Interdepartmental Committee on Nutrition for National Defense (ICNND $\left.^{14}, 1963\right)$ que classifica os níveis de retinol em 4 categorias: alto $(>50,0 \mu \mathrm{g} / \mathrm{dl})$, aceitável $(20,0$ a $49,9 \mu \mathrm{g} / \mathrm{dl})$, baixo $(10,0$ a $19,9 \mu \mathrm{g} / \mathrm{dl})$ e deficiente $(<10 \mu \mathrm{g} / \mathrm{dl})$. A caracterização da deficiência de vitamina A como um problema de saúde pública foi baseada nos critérios recomendados pela Pan American Health Organization/ World Health Organization (PAHO/WHO ${ }^{23}, 1970$ ). Segundo essas instituições, a deficiência de vitamina A constitui problema de saúde pública quando $>5,0 \%$ ou $15,0 \%$ ou mais da população apresentarem níveis sérico de retinol $<10,0 \mu \mathrm{g} / \mathrm{dl}$ ou $<20 \mu \mathrm{g} / \mathrm{dl}$, respectivamente.

Devido à baixa prevalência de nível de retinol sérico deficiente, optou-se por agregar as classificaçzes "baixa" e "deficiente" na categoria de nfveis retinol sérico "inadequado", para fins de análise estatística.

\section{Inquérito Dietético}

O método recordatório de $24 \mathrm{~h}$ foi usado para estimar a ingestão de macro e micronutrientes consumidos pelas crianças. A mãe ou o responsável 
pela criança foi entrevistada em sua residência por nutricionistas e estudantes devidamente treinados. Como recurso para ajudar à mãe a recordar as porçozes de alimentos servidos e aumentar a confiabilidade das informações (Witschi ${ }^{34}, 1990$ ), foi utilizado um álbum com desenhos de alimentos e suas dimensões e medidas-padrão de líquidos (Araújo e col. ${ }^{3}, 1993$ ). A frequiência alimentar foi outro método de inquérito dietético adotado para estimar o consumo mensal, semanal e diário de alimentos fontes de vitamina A. Utilizou-se a proposta do International Vitamin A Consultative Group (IVACG $^{15}, 1989$ ) que classifica os alimentos conforme o conteúdo de retinol equivalente, em alto, moderado e baixo, para caracterizar o padrão de consumo de vitamina $\mathrm{A}$.

Infelizmente a falta de informação nas tabelas de composição de alimentos do país impossibilita quantificar a contribuiçăo específica dos carotenoides na dieța da populaçâo estudada. Contudo, os consultores do IVACG, baseados em informações da FAO, agruparam os alimentos vegetais segundo a percetagem de beta-caroteno, em três categorias: alta, moderada e baixa, permitindo caracterizar, ainda que grosseiramente, o padrão de consumo deste micronutriente.

\section{Análise Estatística}

A análise quali-quantitativa da dieta foi realizada através dos "softwares" Sistema de Apoio em Nutriçāo, versāol.0, desenvolvido pela Escola Paulista de Medicina, e do Epi-Info. Os resultados foram comparados à ingestão diária recomendada pela Organização das Nações Unidas para a Agricultura e Alimentos e Organização Mundial de Saúde (FAO/OMS ${ }^{11}$, 1991).

As análises estatísticas foram realizadas utilizando-se o programa SPSS-PC+ e DEPID versāo 2.12, para cálculo do intervalo de confiança. Devido a distribuição não homogênea dos níveis de retinol sérico, optou-se em utilizar a média geométrica para este indicador bioquímico. A prevalência e a média foram as estatísticas utilizadas para detectar a ocorrência do evento, e o teste de qui-quadrado e a análise de variância foram adotados, respectivamente, para testar a diferença entre as proporçōes e as várias médias, a um nível de significância de 5,0\%.

\section{Resultados}

A média e o desvio-padrão dos níveis séricos do retinol, segundo a faixa etária, estão apresentados na Tabela 1. Os menores valores de retinol sérico foram encontrados para os menores de 12 meses de idade, contudo nenhuma diferença estatisticamente significante foi detectada entre as médias $(p=0,31)$.
Tabela 1- Média e desvio-padrão dos niveis de retinol sérico, segundo a idade das crianças. CansançăoBahia, 1992.

\begin{tabular}{lccr}
\hline $\begin{array}{c}\text { Idade } \\
\text { meses }\end{array}$ & $\mathrm{N}$ & $\begin{array}{c}\text { Médlia* de } \\
\text { retinol sérico } \\
(\mu \mathrm{g} / \mathrm{dl})\end{array}$ & $\mathrm{DP}$ \\
\hline$<12$ & 11 & 18,31 & \\
$12-23$ & 23 & 20,38 & $\mathbf{5 , 5 8}$ \\
$24-35$ & 35 & 19,43 \\
$36-47$ & 32 & 20,29 & 7,93 \\
$48-59$ & 37 & 21,76 & 7,50 \\
$60-72$ & 23 & 25,46 & 8,51 \\
\hline Total & 161 & 22,04 & 8,56 \\
\hline F= 0,97; p=0,31 & & 8,53 \\
"Média geométrica & & \\
DP= desvio-padrão & &
\end{tabular}

A distribuiçāo dos níveis séricos de retinol é apresentada na Tabela 2. Níveis séricos de retinol considerados deficientes e baixos foram detectados em 4,3 e $40,4 \%$ das crianças respectivamente, totalizando $44,7 \%$ dos níveis considerados inadequados. Na̋o foi identificado nenhum caso de nível de retinol sérico considerado alto.

A adequaçāo dos níveis séricos de retinol, segundo a faixa etária, nāo mostrou associaçāo com a idade das crianças $(p=0,06)$; contudo aquelas maiores de 60 meses apresentaram a menor taxa de inadequação (Tabela 3). A deficiência da vitamina A distribui-se homogeneamente entre os meninos e meninas $(p=0,93)$ (Tabela 4).

Os resultados do inquérito dietético (recordatório de 24 h) estão apresentados na Tabela 5 . O consumo de energia, expressa em percentagem das recomendaçōes dietéticas permitidas, apresentou valor abaixo do recomendado para todas as faixas etárias; ressalte-se que a energia proveniente do consumo de coco de ouricuri näo foi computada por ser este alimento consumido "ad libitum", o que pode ter subestimado este cálculo. $O$ consumo da proteína ultrapassou a recomendação para as crianças de 24 a 72 meses. A ingestão média de ferro foi inadequada para as crianças menores de 36 meses de idade. A mais baixa inadequação do consumo de vitamina

Tabela 2- Distribuiçąo dos níveis de retinol sérico entre crianças de 24-72 meses. Cansanção-Bahia, 1992.

\begin{tabular}{lcrc}
\hline $\begin{array}{l}\text { Níveis de retinol } \\
\text { sérico }\end{array}$ & No & $\%$ & IC \\
\hline Aceitável & 89 & 55,3 & 47,$6 ; 63,0$ \\
Baixo & 65 & 40,4 & 32,$8 ; 47,9$ \\
Deficiente & 7 & 4,3 & 1,$2 ; 7,5$ \\
\hline Total & 161 & 100,0 & \\
\hline
\end{tabular}

Obs: Năo foram detectados niveis altos de retinol sérico

IC = intervalo de confiança 
Tabela 3- Distribuição dos níveis de retinol sérico, conforme a faixa etária.Cansançăo-Bahia, 1992.

\begin{tabular}{lccccc}
\hline $\begin{array}{c}\text { Faixa etária } \\
\text { (meses) }\end{array}$ & $N^{2}$ & \multicolumn{4}{c}{ Níveis de retinol } \\
\cline { 2 - 6 } & & $\begin{array}{c}\text { Aceitável } \\
n^{9}\end{array}$ & \multicolumn{2}{c}{$\begin{array}{c}\text { Inadequado* } \\
n^{\circ}\end{array}$} & $\%$ \\
\hline$<12$ & 11 & 5 & 45,5 & 6 & 54,5 \\
$12-23$ & 23 & 10 & 43,5 & 13 & 56,5 \\
$24-35$ & 35 & 19 & 54,3 & 16 & 45,7 \\
$36-47$ & 32 & 21 & 65,6 & 11 & 34,4 \\
$48-59$ & 37 & 16 & 43,2 & 21 & 56,8 \\
$60-72$ & 23 & 18 & 78,3 & 5 & 21,7 \\
\hline Total & 161 & 89 & 55,3 & 72 & 44,7 \\
\hline
\end{tabular}

$x_{2}=10,20$

$p=0,06$

* Niveis baixo e deficiente de retinol sérico.

Tabela 4- Distribuição dos niveis de retinol séricosegundo sexo. Cansanção-Bahia, 1992.

\begin{tabular}{|c|c|c|c|c|}
\hline \multirow{2}{*}{ Sexo } & \multirow{2}{*}{ № } & \multicolumn{3}{|c|}{ Níveis de retinol } \\
\hline & & $\begin{array}{c}\text { Acei } \\
n^{0}\end{array}$ & $\begin{array}{l}\text { tâvel } \\
\%\end{array}$ & $\begin{array}{c}\text { Inadequado* } \\
n^{\circ}={ }_{\%}\end{array}$ \\
\hline Masculino & 90 & 50 & 55,6 & $40 \quad 44,4$ \\
\hline Feminino & 71 & 39 & 54,9 & $32 \quad 45,1$ \\
\hline Total & 161 & 89 & 55,3 & 7244,7 \\
\hline
\end{tabular}

$\mathrm{X}_{2}=0,006$

$p=0,93$

- Níveis baixo e deficiente de retinol sérico.

Tabela 5- Adequaçāo percentual média do consumo de energia, proteína, vitamina A, Vitamina $\mathrm{C}$ e ferro, segundo a idade. Cansanção-Bahia, 1992.

\begin{tabular}{|c|c|c|c|c|c|c|}
\hline $\begin{array}{l}\text { Idade } \\
\text { (meses) }\end{array}$ & $N^{2}$ & Energia & Proteina & Vit.A & Vit..C & Ferro \\
\hline $\begin{array}{l}<12 \\
12-23 \\
24-35 \\
36-47 \\
48-59 \\
60-72\end{array}$ & $\begin{array}{c}7 \\
21 \\
32 \\
20 \\
22 \\
21\end{array}$ & $\begin{array}{l}77,4 \\
65,2 \\
65,2 \\
72,8 \\
62,1 \\
62,4\end{array}$ & $\begin{array}{c}91,1 \\
114,3 \\
121,5 \\
148,8 \\
122,1 \\
150,6\end{array}$ & $\begin{array}{l}58,4 \\
45,5 \\
49,5 \\
44,0 \\
40,6 \\
47,8\end{array}$ & $\begin{array}{l}28,8 \\
45,0 \\
61,1 \\
72,0 \\
84,6 \\
83,1\end{array}$ & $\begin{array}{r}85,0 \\
50,0 \\
66,0 \\
118,0 \\
108,0 \\
123,0\end{array}$ \\
\hline
\end{tabular}

Obs: não está computada a energia proveniente do consumo de coco de ouricuri, alimento rico emácidos graxos.

C foi observada para os menores de 12 meses. A adequação do consumo deste micronutriente aumenta com a idade, sem contudo atingir os valores recomendados (Tabela 4).

As Tabelas 6 e 7 ilustram a frequiência do consumo de alimentos fontes de vitamina A, cuja principal fonte é representada pelos carotenóides, em especial o beta-caroteno. $O$ alimento de alto conteúdo em vitamina A na dieta dos pré-escolares é representado pelo fígado; pequena proporção $(7,1 \%)$ das crianças menores de dois anos consome este alimento uma vez por semana. Para as maiores de dois anos, este percentual eleva-se para $24,2 \%$.

Dos alimentos de conteúdo moderado em vitamina $\mathrm{A}$, somente a batata doce e a manga atingem maior percentual de consumo alimentar no grupo de crianças menores de dois anos de idade. Para as crianças de 24 a 72 meses de idade, verifica-se maior diversificação no consumo destes alimentos (Tabela 6 e 7 ).

Os alimentos que compõem a lista de baixo conteúdo em vitamina $A$ são consumidos pelas crianças dos dois grupos etários, contudo a maior frequêência foi observada para o grupo de 24 a 72 meses de idade.

\section{Comentários}

Segundo a definição do $\mathrm{PAHO} / \mathrm{WHO}^{23}$ (1970), a deficiência da vitamina $A$, para as crianças rurais das localidades do semi-árido estudado, constitui problema de saúde pública, desde quando foi detectado,

Tabela 6-Freqüência do consumo de alimentos fontes de vitamina A, segundo a faixa etária de 6 a 23 meses.

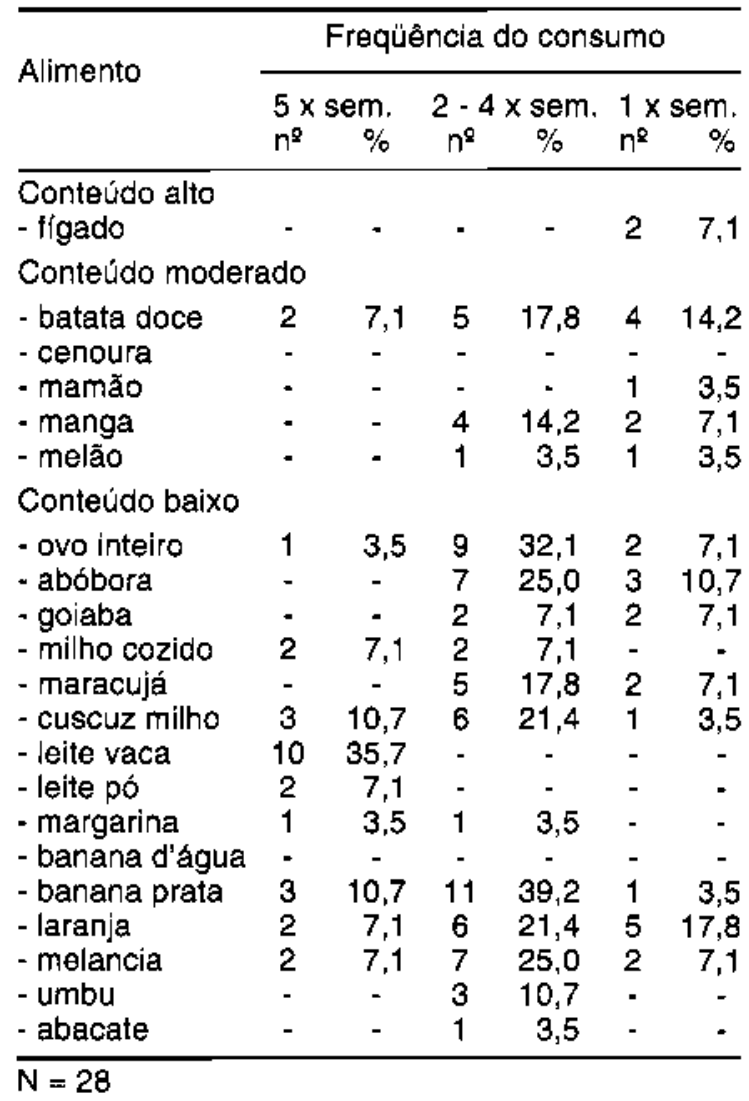


Tabela 7-Freqüência do consumo de alimentos fontes de vitamina A, segundo a faixa etária de 24 a 72 meses.

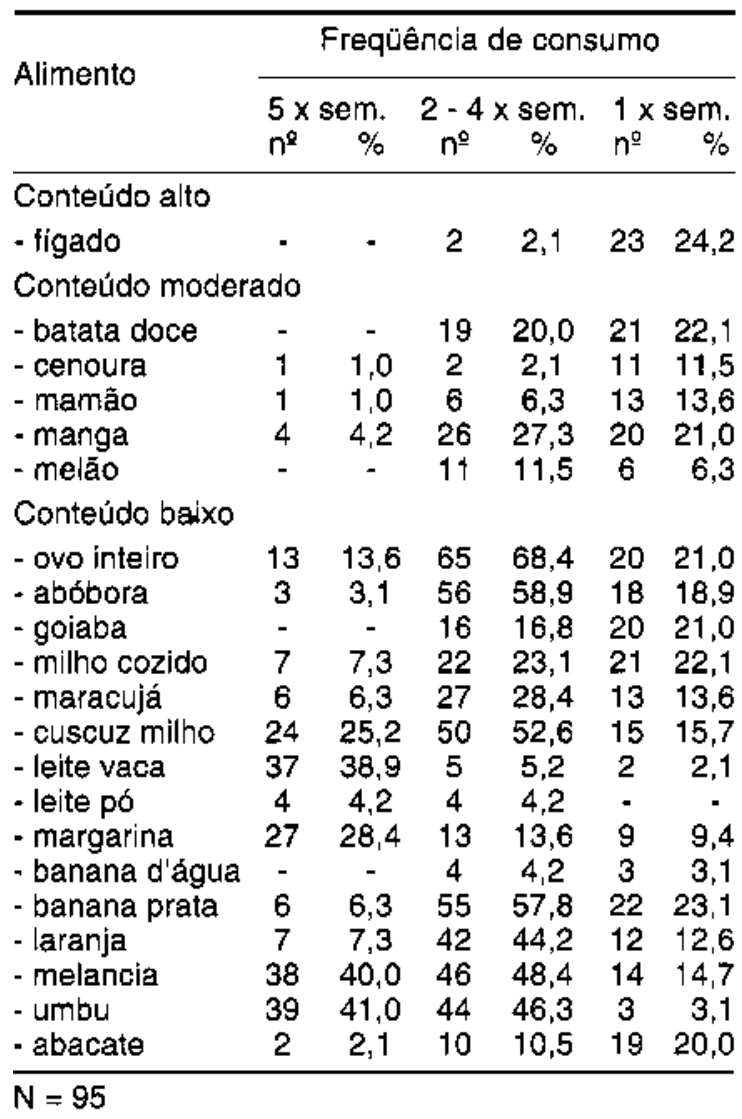

nesta população, um percentual maior do que $15,0 \%$ de níveis séricos de retinol considerados inadequa$\operatorname{dos}(<20,0 \mu \mathrm{g} / \mathrm{d} 1)$.

Este percentual é mais baixo do que o observado por Santos* $(54,7 \%)$, para pré-escolares de áreas urbanas do semi-árido baiano, e inferior também aos $51,4 \%$ detectados por Roncada e col. ${ }^{27}(1978)$, em crianças migrantes em trânsito pela capital do Estado de São Paulo.

Para a população estudada, as principais fontes de vitamina $\mathrm{A}$ são constituídas basicamente por carotenóides cuja conversão é de aproximadamente 20-50\% da quantidade ingerida (Blomhoff e $\mathrm{col}^{7}$. 1992). A maior frequiência no consumo de alimentos ricos em beta-caroteno, tais como: manga, mamão, batata doce entre outros, talvez explique os menores percentuais de níveis séricos de retinol considerados inadequados para as crianças de 24 a 72 meses de idade. A presença de vitamina $C$ na dieta e a gordura oriunda do coco de ouricuri, além de uma boa adequação de ferro dietético, seguramente

\footnotetext{
* Dra. Leonor Maria Pacheco Santos, Escola de Nutrição da Universidade Federal da Bahia (Comunicaçâo pessoal).
}

contribuíram para uma melhor utilização da vitamina $\mathrm{A}$, sem contudo assegurar os níveis adequados de retinol sérico para este grupo etário.

Maiores percentuais de níveis de retinol sérico inadequados foram detectados em crianças menores de 24 meses de idade. O padrão alimentar dessas crianças é caracterizado por dietas lácteas, altamente diluídas e elevados percentuais de hidrato de carbono (Prado e col. ${ }^{24}$. 1975). Este padrâo de consumo, aliado à supressão precoce do leite materno (Assis e col. ${ }^{1}, 1994$ ) e consumo reduzido de alimentos fontes de carotenóides, podem explicar os maiores níveis de inadequação de retinol sérico.

A alta prevalência de parasitose intestinal observada neste grupo populacional (Gaudenzi e col. ${ }^{13}, 1992$ ) é outro fator que pode estar comprometendo a absorção e a utilização da vitamina A ingerida. É conhecido que crianças portadoras de doenças infecciosas e parasitárias, mesmo nas suas formas subclínicas, apresentam menores níveis de retinol sérico.

Se durante o período de safra, quando há aumento da disponibilidade de alimentos fontes de vitamina $\mathrm{A}$, forem detectados percentuais de níveis de retinol sérico que colocam a deficiência de vitamina A como problema de saúde pública, efeitos dramáticos poderão ser esperados durante a entressafra, quando há escassez desses e de outros alimentos.

Os resultados desta investigação evidenciam o risco a que está exposto esse grupo de crianças, uma vez que a vitamina $A$ tem função específica na redução da morbi-mortalidade infantil.

A curto prazo recomenda-se a suplementação em massa com vitamina A para a população estudada, em especial em época de seca e entressafra. A adoção de política agrícola que assegurem a produção, aumento do consumo de alimentos ricos neste micronutriente e melhoria das condições básicas de vida devem ser priorizadas como medidas que a médio prazo serão capazes de erradicar a deficiência nutricional na área.

\section{Referências Bibliográficas}

1. ASSIS, A. M. O. et al. Prática do aleitamento materno em comunidades rurais do semi-árido baiano. Rev. Saúde Pública, 28: 308-4, 1994.

2. ARAÚJO, C. R. C. \& FLORES, H. Improved spectrophotometric vitamin A assay. Clin. Chem., 24: 386, 1978.

3. ARAÚJO. M. P. N. et al. Dimensionamenro de medidas caseiras. Salvador, Departamento das Ciências da Nutrição/Escola de Nutrição-LFBA, 1993.

4. BARRETO. M. L. et al. Effect of vitamin A supplementation on diarhoea and acute lower-respiratory-tract infection in young children in Brazil. Lancet, 344: 228-31,1994.

5. BATISTA FLLHO, M. \& TORRES, M. A. A. Acesso a terra e situaçăo nutricional em populaçōes do smi-átido nordestino. Rev. Pernambucana Desenv., 9: 101-19, 1982.

6. BEATON, G. H. et al. Effectiveness of vitamin A supplementation in the control of young child morbidity and mortality in developing countries. Toronto, International Nutrition Program, 1992. 
7. BLOMHOFF, R. et al. Vitamin A: physiological and biochemical processing. Ann. Rev. Nutr, 12: 37-57, 1992.

8. DAULAIRE, N. M. P. et al. Childhood mortality after a high dose of vitamin $A$ in a high risk population. BMJ (London). 304: 207-10, 1992.

9. DELUCA, L. M. \& McDOWELL, L, M. Effects of vitamin A status on hamster tracheal epithelium in vivo and vitro. Food Nutr.Bull, 11: 20-4, 1989.

10. EL BUSHRA, H. E. et al. Interrelationship between diarthea and vitamin $A$ deficiency a risk factor for diarrhea? Pediat. Infect. Dis. 11: 380-4, 1992.

11. FAO/OMS. Necesidodes de vitamin $A$, hierro folato y vitamin B12. Roma, 1991. (Estudios FAO/Alimentación y Nutrición $\mathrm{N}^{\circ} 23$ ).

12. FUNDAÇÃO IBGE. Censo demogrófico Bahia 1991. Rio de Janeiro, 1992.

13. GAUDENZI E. N. et al. Projeto Cansanção: uma vivência da universidade no sertäo da Bahia. Salvador, Coordenação Central de Extensão, 1992

14. INTERDEPARTAMENTAL COMMITTEEONNLTRITION FOR NATIONAL DEFENSE Mamualfornutrition survey. Washington, D. C., Govemement Ptinting Office, 1963.

15. INTERNATIONAL VITAMIN A CONSULTIVE GROUP, Guidelines for the development of a simplified dietary assessment to identify groups at risk for inadequate intake of vitamin A: report of the international vitamin A Consultative Group. Washington, 1989.

16. JOL'T WHO/UNICEF/USAID/Helen Keller International/ IVAGG. Meeting on the Control of Vitamin A Deficiency and Xerophthalmia, Jakarta, 1980. Report. Geneva, 1982. (WHO-Tech. Rep. Ser., 672).

17. MELE. L et al. Nutritional and household risk factors for xerophthalmia in Aceh, Indonesia: a case-control study. Am. J. Clin. Nutr., 53:1460-5, 1991.

18. MILTON, R.C. etal. Mild vitamin A deficiency and childhood morbidity-an Indian experience. Am. J. Clin. Nutr, 46: $287.9,1987$

19. MLHIAL, P. et al. Vitamin A-fortified monosodium glutamate and health. gowth and survival of children: a controlled field trial. Am. J. Clin. Nutr, 48: 1271-4, 1988.

20. NEWMAN, V. Vitamin $A$ and breastfeeding: a comparison of data from developed and developing countries. San Diego, Cooperative Agreement, United Satates Agency for International Development Office of
Nutrition, 1993.

21. NAUSS, M. K. Influence of vitamin a status on the immune system. In: Bauernfeind, J. C. Vitamin A deficiency and its control. Orlando, Academic Press, 1986, p. 207-36.

22. OSLON, J.A. Phisiologiccal and metabolic basis of myor sigs of vitamin A deficiency. In: Bauernfeind, J. C. Vitamin A deficiency and its control. Orlando. Acadernic Press, 1986. p. 350-84

23. PAN AMERICAN HEALTH ORGANIZATION. Hypovitaminosis $A$ in the Americas. Washington, 1970.

24. PRADO, M. S. et al. Padrão e seleção de alimentos complementares e secedâneos do leite materno em comunidades rurais do semi-árido baiano. Rev. Nutr. PUCCAMP, 8 : 47-64, 1995,

25. RAHMATHULLAR, L. M. B. et al. Reduced mortality among children in Southem India receiving a small weekly dose of vitamin A. J. Med. 323: 929-35, 1990

26. REL'NION CONSULTIVA CONJUNTA FAO/OMS/LNU DE EXPERTOS EN NECESIDADES DE ENERGIA Y DE PROTEINAS, Roma, 1981, Informe, Ginebra, OMS. 1985 (OMS - Ser. Inf. Téc., 724).

27. RONCADA. M. J, et al. Hipovitaminose A em filhos de migrantes nacionais em trânsito pela capital do Estado de São Paulo, Brasil: estudo clínico-bioquímico, Rev,Saúde Pública, 12: 345-50, 1978.

28. SANTOS, L. M. P. et al. Xerophthalmia in the state of Paraiba Northeast of Brazil: clinical findings. Am. J. Clin. Nurr., 38: 139-44, 1983.

29. SOMMER, A. et al. Increased mortality in children with mild vitamin A deficiency. Lancet, 2:585-8, 1983.

30. SOMMER, A. et al. Impact of vitamin A supplementation on childhood mortality. Lancet, 1: 1169-91, 1986.

31. VENKATASWANY, G. et al. Retinol-binding protein in serum of xerophthalmic. malnourished children before and after treatment at a tutrition center. Am. J. Clin. Nutr., 30: 1968-73, 1977

32. VITAMIN A FIELD SUPPORT PROJECT (VITAL). International Science and Technology Institute, Vital nutrients. Arlington. 1991.

33. WEST, K. P. et al. Efficacy of vitamin A in reducing pre-school child mortality in Nepal. Lancet, 338: 67-71, 1991.

34. WITSCHI, J. C, Short-term dietary and recording methods. In: Willett, W. Nutritional epidemiology; Oxford. Oxford University, 1990. p. 52-65.

\title{
Abstract
}

\begin{abstract}
The distribution and magnitude of vitamin A deficiency and dietary consumption of 161 children at 6 to 72 months of age in rural zones in Cansança-Bahia-Brazil were evaluated. The serum retinol levels were measured by the spectrophotometric method (Bassey-Lowry modified by Araújo and Flores). The serum retinol average was found to be distributed homogeneously throughout the different age groups. inadequate serum retinol levels $(<20,0 \mu g / d i)$ were detected in $44.7 \%$ of the children, which characterized the deficiency as constituting a public health problem. The serum retinol levels showed no statistically significant association as between the sex and age of the children; however the chilfren of less than 24 months showed a higher prevalence of inadequate serum retinol levels. The main available source of vitamin $A$ for these children was represented by carotenoids, especially beta-carotene. Foods regarded as being rich in vitamin $A$ were consumed by all age groups. The greatest diversification of consumption of foordstuffs with moderate and low vitamin $A$ content was observed in the group of children of from 24 to 72 months of age, through this was no guarantee of adequate serum retinof levels in this group however.
\end{abstract}

Vitamin A deficiency, epidemiology. Diet survays. Rural population. 